\title{
Intensity of antiplatelet therapy and percutaneous coronary intervention
}

\author{
Wilbert S Aronow
}

Address: Department of Medicine, Divisions of Cardiology, Geriatrics, and Pulmonary/Critical Care, New York Medical College, Valhalla, New York 10595, USA

Email: wsaronow@aol.com

FI000 Medicine Reports 2009, I:8 (doi: 10.3410/MI-8)

The electronic version of this article is the complete one and can be found at: http://FI000.com/Reports/Medicine/content/I/8

\begin{abstract}
Thienopyridine derivatives such as clopidogrel have been shown to reduce the incidence of death in patients undergoing percutaneous coronary intervention when used in conjunction with aspirin. Recently, a new thienopyridine, prasugrel, significantly reduced the primary endpoint of cardiovascular death, non-fatal myocardial infarction or non-fatal stroke to $9.9 \%$ compared to 12.1\% for clopidogrel. Prasugrel has been shown to be more efficacious than clopidigrel in reducing ischemic events and stent thrombosis, but does cause more life-threatening bleeding in patients undergoing percutaneous coronary intervention.
\end{abstract}

\section{Introduction and context}

Aspirin reduces the aggregation of platelets exposed to thrombogenic stimuli by inhibiting the cyclo-oxygenase enzyme reaction within the platelet, thereby blocking the conversion of arachidonic acid to thromboxane $A_{2}$. Clopidogrel and ticlopidine are thienopyridine derivatives that inhibit platelet aggregation by inhibiting the binding of adenosine 5'-diphosphate (ADP) to its platelet receptor.

The final common pathway of platelet aggregation is mediated by activation of platelet glycoprotein IIb/IIIa receptors by a platelet agonist such as ADP, collagen, or thrombin followed by cross-linking of activated receptors by circulating fibrinogen molecules. Although intravenous platelet glycoprotein IIb/IIIa inhibitors are effective in treating patients with acute coronary syndromes undergoing percutaneous coronary intervention (PCI), especially in diabetics [1], oral platelet glycoprotein IIb/IIIa inhibitors have been found to increase mortality [2].

In the Clopidogrel in Unstable Angina to Prevent Recurrent Events (CURE) trial, 2658 patients, mean age
$62 \pm 11$ years, underwent PCI [3]. The primary endpoint of cardiovascular death, myocardial infarction (MI), or urgent target vessel revascularization within 30 days of PCI was significantly reduced from $6.4 \%$ in patients treated with aspirin plus placebo to $4.5 \%$ in patients treated with aspirin plus clopidogrel (loading dose $300 \mathrm{mg}$ and maintenance dose $75 \mathrm{mg}$ daily), a relative risk reduction of $30 \%$ and an absolute risk reduction of $1.9 \%$ [number needed to treat (NNT) 53 persons] with no significant difference in major bleeding between the two groups. At 8-month follow-up, clopidogrel plus aspirin significantly reduced cardiovascular death or MI by $31 \%$, from 12.6 to $8.8 \%$ (NNT 26 persons). These data are from a post-randomization analysis.

In the Clopidogrel for the Reduction of Events During Observation (CREDO) trial, 2116 patients, mean age $62 \pm 11$ years, undergoing elective PCI or deemed at high likelihood of undergoing PCI, were randomized to aspirin plus clopidogrel (loading dose $300 \mathrm{mg}$ and maintenance dose $75 \mathrm{mg}$ daily) or to aspirin plus placebo for 12 months [4]. At 1-year follow-up, clopidogrel significantly reduced the incidence of death, MI, and stroke from 11.5 to $8.5 \%$, with a relative 
risk reduction of $27 \%$ and an absolute risk reduction of $3.0 \%$ caused by clopidogrel (NNT 33 persons).

The current American College of Cardiology/American Heart Association guidelines for PCI recommend the use of aspirin and clopidogrel (loading dose of $300 \mathrm{mg}$ followed by a maintenance dose of $75 \mathrm{mg}$ daily) at the time of PCI, followed by 75 to $162 \mathrm{mg}$ of aspirin daily continuing indefinitely after PCI. The guidelines also recommend $75 \mathrm{mg}$ of clopidogrel daily for at least 1 month after bare-metal stent implantation, for at least 3 months after sirolimus stent implantation, for at least 6 months after paclitaxel stent implantation, and ideally for at least 1 year in patients not at high risk of bleeding [5]. Intravenous platelet glycoprotein IIb/IIIa inhibitors may be used at the time of PCI [5]. Of our last 1000 patients who had PCI, 100\% were treated with aspirin, $100 \%$ with clopidogrel (usually with a loading dose of $600 \mathrm{mg}$ daily), and 13\% with intravenous platelet glycoprotein IIb/IIIa inhibitors.

\section{Recent advances}

Prasugrel is a new thienopyridine that inhibits ADPinduced aggregation more consistently, and to a greater extent, than standard and higher doses of clopidogrel in patients undergoing PCI [6]. In the Trial to Assess Improvement in Therapeutic Outcomes by Optimizing Platelet Inhibition with Prasugrel-Thrombolysis in Myocardial Infarction (TRITON-TIMI) 38, 13,608 patients with moderate- to high-risk acute coronary syndromes with scheduled PCI treated with aspirin were randomized to prasugrel (loading dose of $60 \mathrm{mg}$ followed by a maintenance dose of $10 \mathrm{mg}$ daily) or to clopidogrel (loading dose of $300 \mathrm{mg}$ followed by a maintenance dose of $75 \mathrm{mg}$ daily) [7]. At 14.5-month median followup, the primary endpoint of cardiovascular death, nonfatal MI, or non-fatal stroke was significantly reduced to $9.9 \%$ in those randomized to prasugrel, compared to $12.1 \%$ in those treated with clopidogrel (absolute risk reduction 2.2\%; relative risk reduction $19 \% ; P<0.001$; NNT 45 persons). Life-threatening bleeding occurred in $1.4 \%$ of patients receiving prasugrel versus $0.9 \%$ receiving clopidogrel (hazard ratio $=1.52, P=0.01$ ).

Stent thrombosis was significantly reduced by prasugrel in patients with drug-eluting stents by $64 \%$ (from 2.31 to $0.84 \%$ ), and by $48 \%$ in patients with bare-metal stents (from 2.41 to $1.27 \%$ ) [8]. These data are difficult to interpret since the use of bare-metal stents and of drugeluting stents was not randomized. The overall reduction in stent thrombosis by prasugrel was 52\% (from 2.35\% in patients receiving clopidogrel to $1.13 \%$ in those receiving prasugrel). When events that occurred while patients had been off the study drug for longer than 7 days were excluded, a 55\% decrease in stent thrombosis in favor of prasugrel was found $(0.98 \%$ versus $2.14 \%$; hazard ratio $=0.45 ; P<0.0001$ ).

Among patients with a history of stroke or transient ischemic attack, intracranial hemorrhage was increased from $0 \%$ on clopidogrel to $2.3 \%$ on prasugrel $(P=0.02)$ [7]. Patients aged 75 years and older and patients with a body weight less than $60 \mathrm{~kg}$ had a similar incidence of cardiovascular death, non-fatal MI, or non-fatal stroke if they were treated with prasugrel $(16.1 \%)$ or clopidogrel $(16.0 \%)$, but a $42 \%$ insignificant increase in major bleeding related to non-coronary artery bypass graftingrelated non-fatal thrombolysis in MI on prasugrel $(4.3 \%)$, compared to clopidogrel $(3.3 \%)$ [7]. These data were identified post hoc.

\section{Implications for clinical practice}

On the basis of the available data, prasugrel is more efficacious than clopidogrel in reducing ischemic events and stent thrombosis but causes more life-threatening major bleeding than clopidogrel in patients undergoing PCI. Clinical judgment needs to be used in determining which antiplatelet drug to use if prasugrel is approved by regulatory agencies. Younger persons at high risk for ischemic events with no comorbidities and a low risk for major bleeding would benefit from the use of a more potent antiplatelet drug, such as prasugrel. However, I would use clopidogrel rather than prasugrel in patients with a history of stroke or transient ischemic attack, in patients aged 75 years and older, in patients with a body weight less than $60 \mathrm{~kg}$, and in patients at high risk for bleeding, such as those with comorbidities like significant renal dysfunction.

\section{Abbreviations}

ADP, adenosine 5'-diphosphate; MI, myocardial infarction; NNT, number needed to treat; PCI, percutaneous coronary intervention.

\section{Competing interests}

The author declares that he has no competing interests.

\section{References}

I. Bhatt DL, Topol EJ: Current role of platelet glycoprotein lib/IIla inhibitors in acute coronary syndromes. JAMA 2000, 284:I54958.

2. Chew DP, Bhatt DL, Sapp S, Topol EJ: Increased mortality with oral platelet glycoprotein IIb/IIla antagonists. A metaanalysis of phase III multicenter randomized trials. Circulation 200I, I03:20I-6.

3. Mehta SR, Yusuf S, Peters RJG, Bertrand ME, Lewis BS, Natarajan MK, Malmberg K, Rupprecht H, Zhao F, Chrolavicius S, Copland I, Fox KA; Clopidogrel in Unstable Angina to prevent Recurrent Events trial (CURE) Investigators: Effects of pretreatment with clopidogrel 
and aspirin followed by long-term therapy in patients undergoing percutaneous coronary intervention: the PCI-CURE study. Lancet 200I, 358:527-33.

4. Steinhubl SR, Berger PB, Mann JT III, Fry ET, DeLugo A, Wilmer C, Topol Ej; Clopidogrel for the Reduction of Events During Observation Investigators: Early and sustained dual oral antiplatelet therapy following percutaneous coronary intervention. A randomized controlled trial. JAMA 2002, 288:24II-20.

5. King SB III, Smith SC Jr, Hirshfeld JW Jr, Jacobs AK, Morrison DA, Williams DO: 2007 focused update of the ACC/AHA/SCAI 2005 guideline update for percutaneous coronary intervention. A report of the American College of Cardiologyl American Heart Association Task Force on Practice guidelines. Circulation 2008, I1 7:26I-95.

6. Wiviott SD, Trenk D, Frelinger AL, O'Donoghue M, Neumann F-J, Michelson AD, Angiolillo DJ, Hod $H$, Montalescot G, Miller DL, Jakubowski JA, Cairns R, Murphy SA, McCabe CH, Antman EM, Braunwald E; for the PRINCIPLE-TIMI 44 Investigators: Prasugrel compared with high loading- and maintenance-dose clopidogrel in patients with planned percutaneous coronary intervention. The Prasugrel in Comparison to Clopidogrel for Inhibition of Platelet Activation and Aggregation- Thrombolysis in Myocardial Infarction 44 Trial. Circulation 2007, I 16:2923-32.

7. Wiviott SD, Braunwald E, McCabe CH, Montalescot G, Ruzyllo W, Gottlieb S, Meumann F-J, Ardissino D, De Servi S, Murphy SA, Riesmeyer J, Weerakkody G, Gibson CM, Antman EM; for the TRITON-TIMI 38 Investigators : Prasugrel versus clopidogrel in patients with acute coronary syndromes. N Engl J Med 2007, 357:200I-I5.

FI000 Factor 9.0 Exceptional Evaluated by Deepak Bhatt 2I Nov 2007

8. Wiviott SD, Braunwald E, McCabe CH, Horvath I, Keltai M, Herrman J-P, de Werf FV, Downey WE, Scirica BM, Murphy SA, Antman EM; for the TRITON-TIMI 38 Investigators: Intensive oral antiplatelet therapy for reduction of ischaemic events including stent thrombosis in patients with acute coronary syndromes treated with percutaneous coronary intervention and stenting in the TRITON-TIMI 38 trial: a subanalysis of a randomized trial. Lancet 2008, 371:1353-63.

FI000 Factor 6.0 Must Read

Evaluated by Paulus Kirchhof 18 Apr 2008 